\section{As crianças sem terrinha e as mobilizações infantis no Brasil}

\section{Márcia Mara Ramos \\ Magíster en Educación \\ Universidad Estatal de Rio de Janeiro \\ - Brasil \\ marciapterra@gmail.com \\ https://orcid.org/0000-0001-6698-0169}

\section{Ligia Leão de Aquino}

Doctora en Educación

Universidad Estatal de Rio de Janeiro

- Brasil

ligia.aquino@uerj.br

https://orcid.org/0000-0002-8767-7203

Artículo de investigación

Recepción: 15 de diciembre de 2018 Aprobación: 30 de enero de 2019 https://doi.org/10.19053/22160159.v10.n23.2019.9728

\section{Resumo}

Este trabalho focaliza a criança no contexto de luta pela terra no Brasil, em mobilizações infantis do Movimento dos Trabalhadores Rurais Sem Terra [MST], o que tem proporcionado às crianças visibilidade, presença na luta $\mathrm{e}$ protagonismo na construção da identidade Sem Terrinha. Como uma das experiências educativas latino-americanas, a prática educativa com as crianças Sem Terrinha vem influenciando movimentos populares vinculados à Via Campesina, viabilizando maior participação das mulheres em diferentes frentes de atuação, bem como a participação da criança, como sujeito histórico e de direito, no contexto da luta pela terra. No MST, a terra, em seu significado de luta, é a possibilidade para a reprodução da existência humana. Nesselugar, a criança faz parte e constrói significado para a luta pela terra, e também se constitui na realização de uma infância da classe trabalhadora. Ao se repensar esse lugar, numa perspectiva contra-hegemônica, se exige desenvolvimento de práticas pautadas numa educação política, com referência na pedagogia socialista e da educação popular na organização das crianças do campo.

Palavras chaves: sem terrinha, infância, reforma agrária popular, educação do campo 


\title{
La niñez sin tierrita y las movilizaciones infantiles en Brasil
}

\section{Resumen}

Este trabajo se centra en el niño en el contexto de la lucha por la tierra en Brasil, en movilizaciones infantiles del Movimiento de los Trabajadores Rurales Sin Tierra [MST], que da a la niñez visibilidad, presencia en la lucha y protagonismo en la construcción de la identidad sin tierrita. Como experiencia educativa latinoamericana, la práctica educativa con la niñez sin tierrita ha influido en los movimientos populares vinculados a la Vía Campesina, al permitir mayor participación a la mujer en diferentes escenarios, así como la participación del niño, como sujeto histórico y de derecho en el contexto de la lucha. En el MST, la tierra, en su significado de lucha, es la posibilidad de reproducir la existencia humana. Allí, el niño hace parte y da sentido a la lucha por la tierra, y también es la realización de una infancia de la clase trabajadora. Al repensar ese lugar desde una perspectiva contrahegemónica, se exige el desarrollo de prácticas guiadas desde una educación política, relacionadas con una pedagogía socialista y de educación popular en la organización de la niñez en el campo.

Palabras clave: sin tierrita, infancia, reforma agraria popular, educación en el campo

\section{Landless children and child mobilizations in Brazil}

\begin{abstract}
This work focuses on children in the context of the fight for land spaces in Brazil, and on child mobilizations of the Landless Workers' Movement (MTS, in its Portuguese acronym), which makes children visible and allows them to be present and play a leading role in the construction of the landless identity. As an educational experience in Latin America, educational practices with landless children have influenced grassroots movements associated with the Peasants' Way by enabling greater
\end{abstract}


participation of women in various scenarios, as well as the participation of children as historical subjects and subjects of law in the context of fight. For MTS, land, in its meaning of fight, is the possibility of reproducing human existence. There, children give meaning to the fight and are a part of it; likewise, it is the accomplishment of children from a working class. To rethink that place from an anti-hegemonic point of view requires the development of guided practice on the basis of political education. Such practice is related to socialist pedagogy and popular education in the organization of children in the countryside.

Keywords: landless, childhood, popular agrarian reform, education in the countryside.

\section{Les enfants sans-terre et les mobilisations infantiles au Brésil}

\section{Résumé}

Ce travail porte sur les enfants dans le contexte de la lutte pour la terre au Brésil, et sur les mobilisations infantiles du Mouvement des sansterre(MST), qui leur donne de la visibilité, une présence dans la lutte et un rôle principal dans la construction de l'identité sans-terre. En tant qu'expérience éducative en Amérique latine, la pratique éducative avec les enfants sans-terre a influé sur les mouvements populaires liés à la Voie Paysanne, en permettant une plus grande participation des femmes dans différents scénarios ainsi que la participation des enfants comme sujets historiques et de droit dans le contexte de la lutte. Pour le MTS, la terre, dans sa signification de lutte, est la possibilité de reproduire l'existence humaine. Là, les enfants font partie et donnent du sens à la lutte pour la terre; il s'agit également de l'accomplissement des enfants de la classe ouvrière. Le fait de repenser ce lieu d'un point de vue contre-hégémonique exige le développement de pratiques guidées sur la base d'une éducation politique. Telles pratiques doivent être liées à une pédagogie socialiste et d'éducation populaire dans l'organisation des enfants à la campagne.

Mots-clés : sans-terre, enfance, réforme agraire populaire, éducation à la campagne 


\section{Introdução ${ }^{1}$}

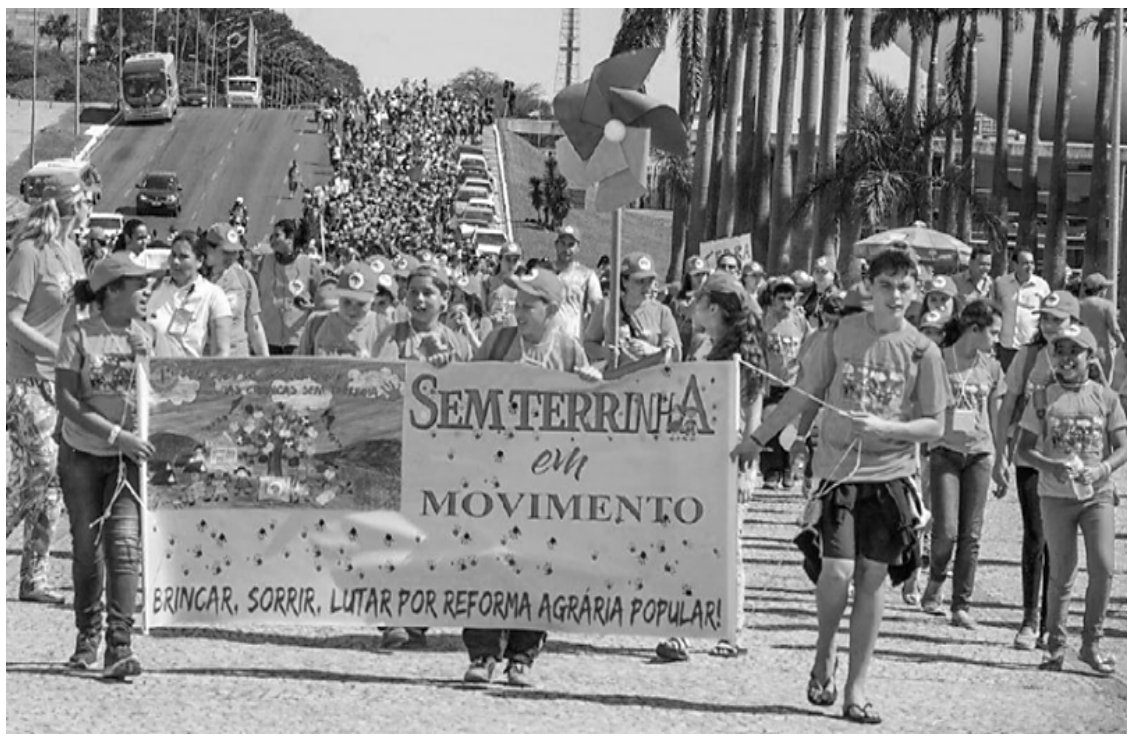

Imagem 1. Sem Terrinhas em Marcha, Brasília, 2018. Foto: Guedes, E. (2018).

O presente artigo tem por objetivo apresentar parte da investigação em curso e socializar o projeto educativo do Movimento dos Trabalhadores Rurais Sem Terra [MST] no trabalho com a infância Sem Terra, alicerçados nas matrizes formadoras que estão vinculados ao programa de Reforma Agrária Popular do MST, o qual sereferenda no VI Congresso Nacional, em 2014², tendo como princípio a filosofia da práxis social, numa relação dialética entre teoria e prática, que orienta o trabalho formativo e educativo com as crianças do campo. O MST tem por objetivo: lutar pela terra, lutar pela reforma agrária e lutar pela transformação social, compreendendo a necessidade da supressão da concentração

1 Este trabalho é resultado da prática militante educadora no MST e das pesquisas: de Monografia (especialização); da Dissertação de Mestrado em Educação; e do Doutorado (em curso) no Grupo de Pesquisa Infância e Saber Docente no Programa de Pós-graduação em Educação/UERJ.

2 O VI Congresso Nacional, com lema "Lutar, construir Reforma Agrária Popular", teve a presença de " 15 mil trabalhadores e trabalhadoras de 23 estados brasileiros, além de 250 convidados internacionais, participam da maior instância de decisão do Movimento" (MST, 2014). Nesse Congresso contou ainda com mais de 700 crianças de o a 12 anos de idade na Ciranda Infantil Paulo Freire. 
fundiária no Brasil para a transformação da sociedade, sendo esta a base que fundamenta a concepção de educação do MST. O projeto educativo do MST é composto por matrizes formadoras vinculadas à práxis social e reafirmadas em ações concretas da luta social, da coletividade, da cultura, da história, do internacionalismo e do trabalho como princípio educativo, para o processo de desenvolvimento no trabalho com a infância Sem Terra.

A pesquisa, realizada em doutoramento em curso, toma o processo histórico, social, cultural e político da infância na luta pela terra no Brasil, com um recorte na experiência das crianças do MST. Considerando que este movimento camponês, desde sua origem (1984), desenvolve prática educativa com as crianças Sem Terrinha e as reconhececomo sujeitos históricos e de direito, como também lutadoras por um mundo melhor. Estas práticas educativas se constituem como experiências educacionais, de cultura e comunicação popular, que não necessariamente estão vinculadas à instituição estado, como se dá na América Latina. As práticas educativas com as crianças Sem Terrinha têm proporcionado aos movimentos populares do campo, vinculados à Via Campesina ${ }^{3}$, espaços específicos para a participação das crianças na luta social, bem como a garantia de maior atuação e participação política da mulher em seus diferentes espaços, mesmo considerando que por mais referências que as organizações sociais camponesa tenham alcançado ao longo de suas lutas, há o desafio aos movimentos populares do campo de organizar espaços destinados às crianças na perspectiva da participação e pertencimento ao movimento, como se registra na imagem 1.

3 A Via Campesina nasceu no ano de 1992 e se constitui em uma articulação mundial dos movimentos camponeses que tem entre seus objetivos:

a construção de relações de solidariedade, reconhecendo a diversidade do campesinato no mundo; a construção de um modelo de desenvolvimento da agricultura que garanta a soberania alimentar como direito dos povos de definir suas próprias políticas agrícolas; e a preservação do meio ambiente com a proteção da biodiversidade. Esses objetivos se opõem à padronização das culturas, ao produtivismo, à monocultura e à produção unicamente para exportação, características do modelo de desenvolvimento do agronegócio. Os movimentos que integram a Via Campesina são pequenos e médios agricultores que se inserem em um movimento internacional, autônomo, pluralista, sem vinculação com partidos, igrejas e governos. São camponeses [...] em várias partes do mundo: Europa do leste, Europa do oeste, nordeste e sudeste da Ásia, América do Norte, Caribe, América Central, América do Sul e África. (Mançano, s. d.) 
Os debates sobre o lugar da infância na luta pela terra busca reconhecê-las como construtora e lutadora na sua comunidade. Sem dúvida, como afirma Wartofsky (2000, p. 105), "a criança é um agente na sua própria construção e na construção do mundo", uma singularidade vinculada ao jeito que o movimento historicamente vem construindo o trabalho educativo com as crianças. É na interação com o mundo e com outras crianças, que geograficamente as distanciam e ao mesmo tempo as aproximam com as questões políticas, econômicas e sociais de realidades como as da Palestina, Haiti, Síria, Cuba, Venezuela, Colômbia e tantos outros países, que se reafirma que a luta por justiça social e contra a propriedade privada é internacional. A vivência no assentamento e acampamento de reforma agrária dialeticamente vai sendo concebida pela práxis social. As crianças aprendem junto com a coletividade da comunidade a organizar-se no processo da luta pela terra em território brasileiro, mas tendo presente a dimensão de mundo que abarca a cada um desses povos.

Tendo como pressupostos os debates sobre o lugar da infância na luta pela terra, com base nas crianças dos assentamentos e acampamento de reforma agrária, sob uma ótica crítica e de um referencial pautado nos estudos da infância, as reflexões sobre participação e protagonismo da infância são questões para pesquisa, pois mesmo nos espaços sociais que a elas são proporcionados, o sistema capitalista e, em especial, na "América Latina, millones de niños y niñas nazcan condenados a la miséria" (Redondo, 2015, p. 15). A educação hegemônica nos provoca: O que é ser criança filha da classe trabalhadora, hoje, na América Latina? Que lugar está reservado à sua formação humana? Em qual projeto social está inserida? Certamente o limite para efetivação da participação da criança está atrelado às condições estruturais e políticas impostas à sua família. Nesse caso, a exemplo do MST, no Brasil, alternativas são construídas para contrapor ao modelo hegemônico capitalista, proporcionando que, desde a infância, a criança se reconheça em sua classe social e participe da vida real nos acampamentos e assentamentos de reforma agrária.

De acordo com Redondo (2015), na realidade da infância na América Latina existe uma dívida histórica e muitas análises apontam o atraso e a exclusão social, sem colocar o principal problema do desenvolvimento do capitalismo latino-americano internacional que concentra a riqueza e produzindo a pobreza, a marginalidade, se apresentando com um maior grau de injustiças 
e desigualdade no mundo (p. 17). O trabalho em condições de exploração infantil é um dos principais problemas que afetam a infância filha da classe trabalhadora.

Las infancias trabajadora son una imagen cotidiana en nuestras tierras. En las grandes urbes, en zonas rurales, en las minas, en el trabajo doméstico, entre otras formas de explotación los niños y niñas son explotados incluso bajo forma veladas de trabajo esclavo; la mendicidad, la prostitución, que ubica de manera alarmante a la niñez latinoamericana en una situación de extrema vulnerabilidad. En el caso de México, en la zona de Chiapas, donde se concentra los índices más altos de pobreza de dicho país, el 32\% de la población chiapana pertenece a grupos indígenas. [...] En el Paraguay, casi cincuenta mil niños, de un total de medio millión que trabajan en el país, lo hacen bajo la forma del "criadazgo", una forma sutil de servidumbre en casas de familias. (Redondo, 2015, p. 19)

A realidade atual na América Latina é marcada por um processo histórico de genocídio, massacre e invasão no território dos povos originários, que foram expulsos de suas terras com violência, que em nome da civilização etnocêntrica impõe uma visão única de sociedade ocidental sobre a cultura e a história dos povos nativos e dos descendentes de africanos escravizados, quando não foram ou são exterminados, são segregados, com o objetivo de apagar a memória e a história, suas práticas, seus valores e crenças para dominar o território de povos que, entretanto, lutam e resistem. As profundas marcas de violência e imposição são presentes na atualidade, mas a resistência das populações do campo e dos movimentos populares urbanos, entre outras frentes como a própria educação, movimentam as lutas atuais em defesa dos direitos conquistados historicamente, e permanecem reivindicando e agindo para a construção de uma sociedade mais justa e igualitária.

No Brasil, o conflito agrário e as profundas marcas históricas de um país colonizado, e que na conjuntura atual em um estado de exceçã $o^{4}$, se acirra com legalidade no enfrentamento do latifúndio

4 Oestado de exceção apresenta uma estrutura dupla, formado por dois elementos heterogêneos e no entanto coordenados: um elemento normativo ejurídico em sentido estrito e outro anômico e metajurídico. O estado de exceção é o dispositivo que deve em última instância articular e manter juntos os dois aspectos da máquina jurídicopolítico. É como espaço vazio, onde uma ação humana sem relação com o direito está diante de uma norma sem relação com a vida. (Agamben, 2004, pp. 130-131) 
com as trabalhadoras e trabalhadores, queimando lavouras, escolas, barracos ou casas, assassinando lideranças, cenário de intensos conflitos em que, certamente, as crianças estão presentes e assim vivenciam a morte de seus parentes e amigos, produzindo o medo, a insegurança diante da brutalidade de um Estado violento que se fortalece a serviço dos interesses da classe dominante. Portanto, podemos considerar que o primeiro tipo de violência que a criança filha da classe trabalhadora sofre na sociedade de classe é a violência de Estado.

O processo de colonização e de sucessivos governos ditatoriais que o povo brasileiro, assim como todos os demais da América Latina, enfrentou e enfrenta, faz parte da trajetória históricamarcada pela colonização de exploração, o escravagismo e pelo desenvolvimento do capitalismo, o que define o lugar da infância da classe trabalhadora, bem como de toda geração humana.

No enfrentamento dessa realidade perversa com a classe trabalhadora, o MST, via ocupação do latifúndio da terra, mobiliza famílias do campo e da cidade e organiza o acampamento de lona preta ou de palha, ou ainda, de pedaços de lonas em suas diferentes cores, que vão sendo decorados conforme a aquisição de tintas, se tornando uma pequena ou grande cidade de moradias improvisadas e itinerantes.

No movimento da luta, os Sem Terra no MST, movimentam danças de diferentes ritmos, cores, sons que expressam desejos, vontades, desordem - subversividade à ordem. O desenho coletivo que vai sendo gestado no imaginário humano, desde a sua luta, tem em sua essência o rompimento com o meu, passando a ser o nosso, a palavra expressiva da arte em construção. Da arte de viver e sobreviver, com cores que nem sempre são as escolhidas, mas as possíveis, de danças e sons que existem para resistir ao tempo e suas contradições, formam-se em beiras de estradas, nas grandes áreas de terras concentradas (produtora de sons e ritmos "intolerantes" intoleráveis à ordem...), nascendo uma espacialidade diferente, forjada por lonas pretas ou palhas... Insistindo num movimento de mudanças, que nasce sempre da ausência de direitos, da concentração fundiária e da propriedade privada, logo, das relações capitalistas de exploração. (Ramos, 2014, pp. 33-34)

A ocupação da terra, em certa medida, busca romper com a estrutura individualista de sociedade, proporcionando às famílias, 
que ali passarão a residir, um processo de mudança na forma de pensar o mundo e suas contradições. Ocupar o latifúndio da terra, para as famílias, é muito mais que romper as cercas, é romper com a história burguesa, com crenças e ideários que até então tinham determinado suas vidas.

É nesse contexto que a educação no MST, tendo como marco o ano de $1987^{5}$, vem sendo gestada pela necessidade de pensar coletivamente uma educação contra-hegemônica, filosófica e popular para os acampamentos e assentamentos. Num primeiro momento, enfatizando a luta por escolas nas áreas de reforma agrária e a partir do exercício de reflexão coletiva sobre a educação no MST, o Setor de Educação tomou para si a responsabilidade de elaborar propostas que contribuam para que o conjunto do movimento reflita e concretize uma educação articulada aos seus princípios. Desse processo resultou a produção coletiva de materiais que sintetizam e reafirmam a concepção de educação do MST, sendo um deles o Caderno $n^{\circ} 8$ (Princípios Fílosóficos e Pedagógicos) que amplia a compreensão na coletividade sobre o projeto educativo do MST.

Os Princípios filosóficos dizem respeito a nossa visão de mundo, nossas concepções mais gerais em relação à pessoa humana, à sociedade, e ao que entendemos que seja educação. Remetem aos objetivos mais estratégicos do trabalho educativo no MST.

Os princípios pedagógicosse referem ao jeito de fazer e pensar a educação, para concretizar os próprios princípios filosóficos. Dizem dos elementos que são essenciais e gerais na nossa proposta de educação, incluindo especialmente a reflexão metodológicados processos educativos, chamando a atenção de que pode haver práticas diferenciadas a partir dos mesmos princípios pedagógicos e filosóficos. (MST, 1999, p. 4)

Para a construção da concepção educacional do MST, o Setor de Educação tomou como referencial pedagógico as proposições de educadores russos, como Pitrak, Makarenko, Krupiskaya eShulguin. Outra referência está na Educação Popular, em especial na obra do educador brasileiro Paulo Freire que, para além de se preocupar com a educação do povo brasileiro, criou a Pedagogia do Oprimido

5 O Primeiro Encontro Nacional de Professores do MST se realizou em julho de 1987 em São Mateus/ ES, quando se formalizou a criação do Setor de Educação no MST. 
e foi defensor do internacionalismona América Latina e na África. A terceira fonte da pedagogia do MST, como afirma Caldart (1999), está no próprio Movimento, que permitiu a reflexão da educação no seu território ocupado, sobre a necessidade coletiva em conhecer o mundo e vincular as práticas educativas desenvolvidas à luta social. A concepção de educação do MST é orientadora da Pedagogia do Movimento, na qual se considera "a educação uma das dimensões da formação, entendida tanto no sentido amplo da formação humana, como no sentido mais restrito de formação de quadros para a organização e pelo conjunto das lutas dos trabalhadores" (MST, 1999, p. 5). Ou seja, a pedagogia é o jeito que o MST vem organizando o fazer em movimento através da teoria e da prática, em ações concretas da vida real do assentamento e acampamento.

\section{A infância do campo}

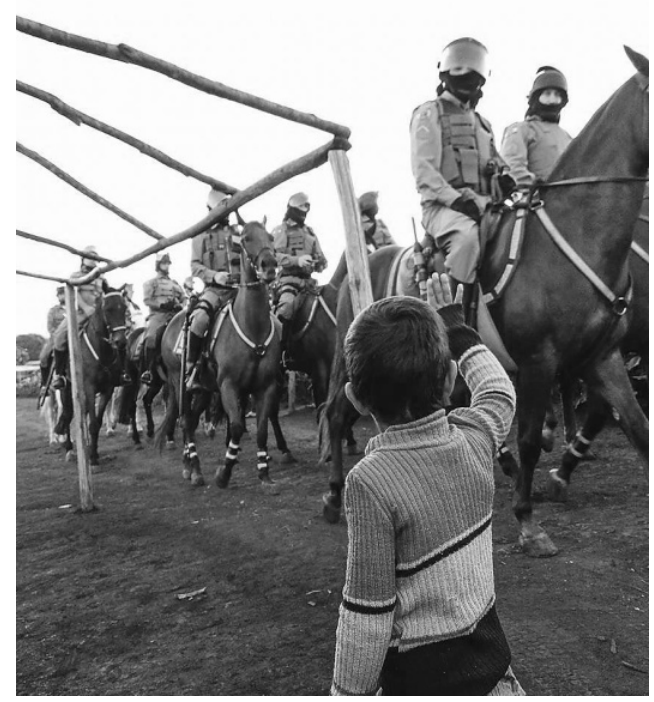

Imagem 2. Criança Sem Terrinha diante de força policial. Crédito: Adriano, J. (s. d.).

A imagem acima expressa a condição da criança na luta pela terra via MST, que é (re)significada a partir de uma perspectiva de resistência e de presença no cotidiano do próprio Movimento, proporcionando a elas uma educação crítica, libertadora e política, que se dá na disputa da pedagogia contra-hegemônica. A resistência e a luta são 
dois elementos fundamentais para compreender a infância vivida nesse contexto. No caso do MST, a terra, em seu significado de luta, é a possibilidade para a reprodução da existência humana. $\mathrm{E}$, nesse lugar, a criança não está fora, ela faz parte e também constrói significado para a luta pela terra, ao mesmo tempo em que é constituída por ele.

O latifúndio é o pecado agrário brasileiro. Na afirmação de Stedile \& Mançano (1999), a natureza do latifúndio é a transformação da terra em falsa mercadoria para exploração, sendo que a terra não é um bem de produção, não é fruto do trabalho humano, do trabalho acumulado. A condição de falsa mercadoria para exploração é um elemento fundante na produção de uma sociedade desigual. A terra é um bem da natureza como a água, o vento, o sol, mas como a terra não se multiplica e não se recria, o ser humano instituiu $a$ propriedade privada da terra, não como mercadoria, mas como uma forma de garantir lucro, acumulação e exploração do trabalho do outro. No Brasil, a terra tem um caráter de espaço de exploração, produzindo uma sociedade com maiores diferenças sociais - maior distância entre pobres e ricos, o que tem determinado as relações sociais campo e cidade, onde o caráter de cultura das elites brasileiras é atravessado pela herança colonial latifundiária, escravagista, criando grandes proprietários de terras com enorme concentração de renda(Stedile \& Mançano, 1999, pp. 10-11).

Para Alentejano (2014, p. 25), a questão fundiária no Brasil tem seu marco histórico na Lei de Terra de 1850, "com o instrumento colonial das sesmarias" e, que permitiu a concentração fundiária no Brasil, tornando-se um grande problema social e histórico e tem sido demarcada através da luta pela terra e que, nos dias atuais, os conflitos da luta pela terra e o aparato judicial imposto, bloqueia o acesso à reforma agrária no país. A colonização também tem o seu o marco com invasão estrangeira, que há mais de 500 anos vem dizimando povos nativos, escravizando povos africanos e, no momento atual, com a internacionalização da agricultura, as compras de terras por empresas estrangeiras transnacionais, no Brasil, continuam expulsando e assassinando os povos do campo dos seus territórios, se apropriando da terra, da água e dos bens naturais do território brasileiro (Alentejano, 2014, pp. 25-30).

Compreender a questão agrária e seus fundamentos no contexto da luta pela terra e o MST - que por uma necessidade concreta faz o enfrentamento ao latifúndio da terra - é também 
pensar o lugar reservado para a infância do campo no contexto agrário e, no caso específico, as crianças do MST fazem a luta pela terra juntamente com suas famílias. Felipe (2009) contribui com algumas considerações para avançarmos nesse tema:
A infância do Brasil agrário está marcada pela estabilidade, pela continuidade sem tensão entre a ordem social e os indivíduos. O tom estável, monofônico, sugere a existência de um mundo homogêneo, sem desvios, principalmente em relação às crianças. [...] Com a Constituição de 1934, ainda de forma bastante incipiente, a infância passa a fazer parte da ação e da função política do Estado. Ela surge no bojo de duas grandes transformações da sociedade brasileira, a industrialização e a urbanização, base material da ascensão de um novo modelo de família, a família conjugal. (pp. 39-52)

A criança faz parte de um processo que não se separa do projeto hegemônico do capital, na sua especificidade, desde a inserção da criança pobre da classe trabalhadora na vida em família, na creche, na escola, no trabalho, entre outros. O direcionamento da formação da criança está associado à sociedade em que ela vive. Sendo a sociedade capitalista vigente, certamente, se as crianças não têm uma plena inserção em sua comunidade, nos movimentos sociais e políticos ou outros tipos de organização que as permita pensar, questionar, serem críticas e que estejam integradas à vida do seu lugar, possivelmente, a sua formação estará condicionada à forma de submissão e aceitação do lugar reservado a elas no capitalismo. Portanto, estudar a infância que está no campo é refletir sobre uma criança que vive em um território disputado pelo capital, um território de exploração, de negação a diferentes direitos - como educação e saúde. É trazer a criança que nem sempre fala ou é escutada, mas pensa, escuta e certamente tem sua visão e sentimento sobre o mundo.

As crianças do campo inscrevem-se, como todas as crianças, em relações complexas, na medida em que participam da simultaneidade de tempo sociais que constitui o mundo global. Elas são sujeitos que atuam no mundo e são afetadas por ele. Assim, falar de infância do campo, das crianças concretas que o habitam, éinexoravelmente falar de sujeitos do mundo, integrados a lugares, e sujeitos que a globalização uniu, partilhando de seus dramas, tragédias, realidade e fantasia. (Silva, Felipe \& Ramos, 2012, pp. 417-418) 
É pensar o lugar em que está a sua família no contexto social, o lugar do trabalho e do projeto educativo hegemônico, nesse contexto atual, sendo que, no processo de modernidade para o desenvolvimento, se pensou a fábrica, a indústria e a educação a serviço desse desenvolvimento. O lugar da infância da classe trabalhadora está no contexto do campo e cidade, da intencionalidade da pedagogia do capital na disputa pela educação desde a infância, no lugar da luta social e da resistência de classe. E, no caso das crianças Sem Terra, em todo Brasil, elas convivem com as diferentes situações de violação dos seus direitos humanos, cuja principal violação é a violência de Estado - da negação à sua família e grupo social ao acesso ao trabalho digno, o que resulta na desproteção quanto à alimentação, à educação, à saúde e à moradia, elementos determinantes na formação da criança. Embora vítima de um Estado violador, a infância Sem Terrinha "é ativa no seu próprio direito, não apenas de maneira imitativa, mas como um agente na sua própria construção" (Wartofsky, 2000, p. 105), questionadora dos problemas que a afetam em sua comunidade. As crianças são criativas e atuantes na luta pela terra e, dialeticamente, (re)inventam o MST cotidianamente.

A violência é estabelecida pelo latifúndio e leva em conta somente o interesse de ter o poder da propriedade privada como forma de exploração para o enriquecimento. Muitas foram apropriadas de forma irregular. Isto empobrece um grande número de pessoas ao privá-las do acesso ao trabalho, à educação, à alimentação e ao lugar de convivência - usando do poder do capital para amedrontar, ameaçar, expulsar ou mesmo exterminar aqueles que questionam e lutam contra a propriedade privada.

É nesse cenário de conflitos, mas também de sonhos, que a educação política da infância Sem Terra vem ganhando expressividade ao longo da trajetória no MST e sua significação vem sendo concebida, de certa forma, com a compreensão de que é necessária a participação do conjunto da sociedade que nela vive para que ocorram mudanças sociais. Portanto, com a ocupação do latifúndio da terra, mobilizando e organizando pessoas que não têm acesso ao trabalho, à moradia, bem como a outros direitos sociais, contribui para o reconhecimento de suas condições como sujeito de direito e histórico que luta pela conquista da terra e da reforma agrária defendendo o território ocupado e constituindo- 
se com uma identidade política de Sem Terra e de Sem Terrinha, numa perspectiva de construção de projeto social, o qual tem como princípios uma filosofia de vida para emancipação humana.

\section{As mobilizações infantis no MST}

A criança Sem Terrinha se forma no movimento da luta na perspectiva da organização do coletivo infantil como lutadoras e construtoras da história da infância no MST. Nesse processo é iniciada a luta pelo direito ao acesso à escola dentro dos acampamentos e assentamentos, combatendo a escola burguesa que discrimina as crianças pobres, Sem Terra, as crianças negras e as crianças indígenas ao negar-lhes o direito à educação.

Benjamin (1984) fortalece a ideia de que a educação política precisa ser acessada desde a infância, exigindo pensar o projeto de educação e de sociedade via ações concretas no campo da arte, cultura, comunicação e da própria educação como base das potencialidades na formação política também com as crianças. Nesse sentido, o MST através das práticas educativas da luta pela terra, proporciona que as crianças Sem Terrinha sejam participantes ativos, atuantes como sujeito de sua própria história. Para Benjamin (1984), a burguesia vê a sua pedagogia como a reprodução de sua prática para a sua prole, herdeira de um projeto no seio da família burguesa. A criança da classe trabalhadora nasce dentro de sua classe social. É a condição de classe que pode determinar a formação e a consciência da classe trabalhadora através das contradições geradas pelas desigualdades que o capitalismo estabelece para sua existência, como exemplo as escolas ocupadas no Brasil ${ }^{6}$, as manifestações das crianças Sem Terrinha na luta por escola7, entre outras.É a sua condição de classe como criança, que vai lhe exigir uma organização coletiva, em sua construção política e social onde a criança está inserida (Benjamin, 1984, pp. 122-123).

As mobilizações infantis no MST iniciaram em 1994, sendo que a primeira destasocorreu em Porto Alegre (RS), realizando-se no

6 Ocorreu no Brasil, entre 2015-2016, lutando por melhores salários dos professores e estrutura das escolas, transporte público e em defesa das disciplinas das Humanas.

7 Nos anos de 2014 e 2018, crianças Sem Terrinha se mobilizaram em Brasília para denunciar junto ao Ministério de Educação, as condições das escolas de assentamento e acampamento e o fechamento de mais 37 mil escolas no campo, no Brasil. 
mês de outubro, que tradicionalmente no Brasil tem o dia 12 como de comemoração das crianças. A luta foi pelo direito à escola nos assentamentos e acampamentos e de não sofrerem descriminação por sua condição de pessoa do campo e pobre. Com o marco dessa mobilização pioneira no MST, as comemorações do dia das crianças passaram a serem realizados com lutas, debates, denúncias, brincadeiras, teatro, arte, cultura e com discussão e atenção na solidariedade internacional entre as crianças brasileiras, palestinas, haitianas, cubanas, colombianas, sírias, moçambicanas... como bem nos apresenta a música feita dos Sem Terrinha do Estado do Pará:

Convidamos as crianças para pintar o muro da desigualdade.

É o Sem Terrinha cantando e ocupando com a sua ginga.

Reforma agrária, justiça e liberdade, uma canção de roda.

Palestina livre: um sonho que também é brasileiro. Oh, Palestina.

Menino livre solta pipa e joga bola

Nossa ciranda convida as suas crianças pra dançar na roda

E de mãos dadas sonhando a liberdade de ser conquista. Oh palestina! (Martins, 2014)

A canção reflete a formação que se tem proporcionado com a adoção de literatura infantil que aborda tais temáticas e fortalece a compreensão de que a luta para a transformação social é internacional. Há ainda outros meios e espaços de formação da infância Sem Terra, como as Cirandas Infantis. Este formato destinado às crianças do MST foi inaugurado em 1997, com a realização do I Encontro Nacional das Educadoras e Educadores da Reforma Agrária (I ENERA). Inicialmente, as Cirandas Infantis destinavam-se a atender crianças pequenas, e foram criadas a partir do fortalecimento das cooperativas de produção agropecuária e com a intenção de garantir a participação da mulher na produção e um lugar seguro para seus filhos. Mas assim como ocorreu com as creches urbanas, à medida que essa prática de cuidado coletivo foi se estabelecendo, foi se evidenciando também como espaço educativo e presente nas marchas, nas assembleias, nos cursos de formação, nos congressos, ou seja, em todas as ações de organização e reunião do MST. Os educadores das cirandas são da própria comunidade e se formam na prática com as crianças, eventualmente, alguns têm formação em Curso Normal ou Pedagogia. A prática na Ciranda Infantil, além de repercutir em suas localidades, passou também a influenciar outros movimentos da Via Campesina, no Brasil e internacionalmente. 
Todo o processo formativo e educativo que o MST vem desenvolvendo na luta por escola do campo se observa na efetivação da Ciranda Infantil como espaço da criança, das produções literárias para infância Sem Terra, e do acúmulo com as mobilizações infantis realizadas nos Estados brasileiros, tornando-se prática e cultura no MST em nível nacional. Emjulho de 2018, o MST realizou, em Brasília, o $1^{\circ}$ Encontro Nacional das Crianças Sem Terrinha, contando com a presença de mais de 1.200 crianças e 300 educadores, vindos de 24 estados brasileiros em que o MST está organizado.

A preparação para $01^{\circ}$ Encontro envolveu desde a organização das crianças em seu assentamento ou acampamento, até os encontros estaduais. As ações preparatórias mobilizadas em cada comunidade, através de brincadeiras, filmes, cantigas, oficinas, proporcionou um espaço das crianças envolvendo escolas, Ciranda Infantil e área comunitária para a realização dos encontros Sem Terrinha. A criatividade é essencial nesse processo, assim como as conversas em torno da realidade do assentamento e da luta do acampamento. A canção/hino produzida pelas crianças Sem Terrinha do Rio de janeiro, que ganhou expressão nacional passou a ser cantada de norte a sul do país, demarcando bem a condição e desejo das crianças: "Sou Sem Terrinha do MST, acordo todo dia para lutar, você vai ver! Por terra, por escola, saúde e educação, desse meu direito eu não abro mão". E dessa forma, os espaços das crianças Sem Terra foram se fortalecendo. A expectativa pelo $1^{\circ}$ Encontro Nacional não era só das crianças, mas também dos adultos e todo o conjunto do MST, que assumiu o desafio de mobilizar e organizar, no mês de outubro e novembro de 2017, bem como a própria realização do $1^{\circ}$ Encontro em 2018, que foi um momento de muito aprendizado. A mobilização infantil no MST, reuniu um total de mais de dez mil Sem Terrinha, em todo o Brasil, com o objetivo de preparar o evento de 2018.

Os espaços de preparação e o próprio $1^{\circ}$ Encontro Nacional, que teve uma coordenação de crianças com representação de uma menina e um menino por Estado, se constituíram um lugar de muitos repertórios para observação e reflexãosobre participação, auto-organização e protagonismo infantil, o que tem nos provocado a pensar profundamente sobre o papel político das crianças Sem Terra nos 25 anos de existência das jornadas Sem Terrinha no MST. Nesse encontro as crianças produziram um documento com doze compromissos assumidos pelos Sem Terrinha, que 
demarcam para o MST, principalmente no contexto conjuntural, a necessidade de fortalecer o projeto da cultura infantil do campo, da diversidade e da educação popular como projeto emancipador da classe trabalhadora. Portanto, a concepção de infância no MST vem ganhando significação, porque a construção é dialética e não "é simplesmente que o mundo - o mundo sociocultural - constrói a criança, mas que a criança, na sua atividade expansiva, é um agente na sua própria construção"(Wartofsky, 2000, p. 122).

$\mathrm{O} 1^{\circ}$ Encontro Nacional se tornou uma grande referência para as crianças Sem Terrinha, bem como para o conjunto do MST. Mas também despertou na extrema direita neoconservadora, que desde a campanha eleitoral do atual presidente, fez ataques à educação do MST e, através da mídia burguesa e conservadora, uma rede privada de televisão veiculou uma matéria de 20 minutos, acusando o MST de fazer doutrinação das crianças, formação de guerrilheiros, negando então a capacidade de pensar e de criar das crianças e sua condição de sujeito histórico e de direito, direito à participação, ao conhecimento, à cultura, à arte, assim como os direitos básicos como moradia, trabalho para sua família, saúde e educação. Defender as escolas e os assentamentos conquistados da onda neoconservadora no Brasil será uma das ações coletivas que não pode ser somente do MST, mas do conjunto da sociedade.

Considerando que burguesia possui o seu sistema educacional e educa seus filhos para atender a sua demanda econômica e política e que ao mesmo tempo pensa uma educação de formação ideológica para os filhos da classe trabalhadora, que atenda à sua condição de elite, as reflexões de Benjamin (1984) são atuais no sentido de valorizar a apropriação de diferentes linguagens na formação da criança da classe trabalhadora, e pela qual se dá sua educação política, fundamental para o desenvolvimento da criticidade e da busca pela liberdade desde a infância.

A relação linguagens, artes e cultura associada à prática política está presente nas mobilizações infantis no MST, sendo um lugar de encontro, de festa, de brincadeiras, de luta e negociações. Cada Estado tem uma forma de se organizar, sempre garantindo uma equipe de negociação das crianças para discutir com as prefeituras, Secretarias Municipais e de Estado da Educação as demandas e pautas que são levantadas pelo coletivo de crianças e educadores. É um momento de preparação que envolve os assentamentos e 
acampamentos e um conjunto de pessoas - crianças, educadores, lideranças/militantes, amigos e aliados, motoristas de ônibus, cozinheiros, oficineiros, jornalistas, etc. A preparação de cada encontro é em si uma motivação para a participação e organização.

As crianças, pautadas nas temáticas do encontro, fazem cartazes, camisetas, discutem sua participação, as apresentações culturais, além da criação de palavras de ordem que as identificavam por localidades, tornando-se consignas nacionais, por exemplo: "Estrela, estrela vermelhinha, o futuro do Brasil está nas mãos dos Sem Terrinha, Brilha no céu a estrela do Che, nós somos Sem Terrinha do MST".

O registro e análise das práticas de organização e participação da criança Sem Terrinha evidenciam a sua relevância para o MST, ao considerar o papel formativo da cultura da infância articulada à luta social e à (re)invenção do MST, como organização popular que reconhece os encontros e jornadas dos Sem Terrinha como espaço de formação e cultura que dá significação à criança no contexto da luta pela terra. A significação da Jornada, nesses 25 anos de formação e gestação, é de uma experiência política em educação que mobiliza as crianças e as permite atuar como sujeitos históricos na luta pela terra no MST.

\section{Considerações}

A significação da criança Sem Terra a partir da perspectiva de resistência e de presença na luta é fundamentais para pensar os modos como a infância é representada, em especial no contexto da luta pela terra. No caso do MST, a criança não é alheia à vida real do movimento, ela é parte e constrói significado para a luta pela terra. Nesse sentido, as duas frentes de atuação das crianças no MST, como a Jornada das Crianças Sem Terrinha e a Ciranda Infantil - itinerante e permanente - são referências na construção da identidade Sem Terrinha por considerara participação da criança na organização do movimento e de sua construção histórica.

A experiência da prática educativa com as crianças dá significado à Pedagogia do MST e desafia no sentido reafirmar o coletivo, a luta social, a resistência e a organização política desde a infância. Certamente a educação política para a infância da 
classe trabalhadora não será defendida pela pedagogia do capital, portanto, será de resistência coletiva a construção de uma educação na perspectiva da emancipação humana. Será de resistência desde a infância, de criação de novas artes populares, da apropriação da brincadeira como essência humana, das muitas perguntas sobre o mundo, da coletividade como projeção da organização, da esperança e da coragem em preparar o solo, semear e ver nascer e florescer a tão esperada primavera.

\section{Referências}

Agamben, G. (2004). Estado de Exceção. São Paulo: Ed. Boitempo.

Alentejano. P. (2014). Questão Agrária e Agroecologia no Brasil do Século XXI. Em Molina, M., Santos dos, C., Michellotti, F., \& Sousa, R, (Ed.), Práticas contra-hegemônicas na formação dos profissionais das ciências agrária: reflexão sobre Agroecologia e Educação do Campo nos cursos do pronera (pp. 1-147). Brasília: NEAD.

Benjamin, W. (1984). Reflexões: A criança, o brinquedo, a educação. São Paulo: Ed. Summus.

Caldart, R. (2009). Pedagogia do Movimento Sem Terra. São Paulo: Ed. Expressão Popular.

Felipe, E. (2009). Entre campo e cidade: infâncias e leituras entrecruzadas - um estudo no assentamento Palmares II, Estado do Pará (Tese de Doutorado em Educação. Universidade Estadual de Campinas, Campinas, Brasil).

Guedes, E. (2018). Crianças Sem Terrinha em direção à Praça dos Três Poderes, para entrega de documento ao Ministério da Educação [Foto]. Em G. Marinho, Durante passeio cultural em Brasília, Sem Terrinha entregam manifesto no MEC. Disponível em http://www. mst.org.br/2018/07/25/durante-passeio-cultural-em-brasilia-semterrinha-entregam-manifesto-no-

Mançano, B. (s. d.). Via campesina. Em Enciclopédia Latinoamericana. Disponível em http://latinoamericana.wiki.br/verbetes/v/viacampesina

Martins, C. [Clauber Martins]. (2014). SEM-TERRINHA Palestina livre (Calango studio). [Vídeo]. Disponível em https://www.youtube. com/watch?v=XNAmoSQQeOk. Acesso em 14/02/2019. 
Movimento Sem Terra. (2014). Congresso reúne 15 mil camponeses em Brasília. Disponível em http://www.mst.org.br/2014/02/07/ congresso-reune-15-mil-camponeses-em-brasilia.html

Redondo, P. (2015). Infancia(s) latinoamericana(s), uma deuda interna, um debate pendiente. Em. V. Müller (Org.), Crianças na América Latina: Histórias Culturas e Direitos, 1, 15-32.

Ramos. M. (2016). Educação, Trabalho e Infância: Contradições, limitese possibilidades no Movimento dos Trabalhadores Rurais Sem Terra. (Dissertação de Mestrado em Educação). Universidade Estadual de Campinas, Campinas, Brasil.

Silva da, A., Felipe, E., \& Ramos, M. (2012). Infância do Campo. Em R. Caldart,I. Pereira, P. Alentejano, \& G. Frigotto (Orgs.). Dicionário da Educação do Campo. Rio de Janeiro: Escola Politécnica de Saúde Joaquim Venâncio; São Paulo: Expressão Popular.

Stedile, J., \& Mançano, B. (1999). Brava gente: A trajetória do MST e a luta pela terra no Brasil. São Paulo: Editora Fundação Perseu Abramo.

Wartofsky, M. (2000). A construção do mundo da criança e a construção da criança no Mundo. Em W. Kohan \& D. Kennedy (Orgs.), Filosofia e Infância. Possibilidades de um encontro. Petrópolis: Ed. Vozes. 